\title{
Eğitimdeki Eşitsizliğin Değerlendirilmesi
}

\author{
Görkemli Kazar*, Rukiye Çapanoğlu
}

\author{
Munzur Üniversitesi, İ.I.B.F. Uluslararası Ilişkiler Bölümü, Aktuluk/TUNCELI \\ ORCID ID: G. Kazar(0000-0002-5667-3234), R. Çapanoğlu (0000-0002-4009-2929)
}

\begin{abstract}
Özet
İnsanların çok az kontrol sahibi oldukları servet, cinsiyet, etnik köken ve konum gibi koșulların, eğitim ve yaşam fırsatlarını șekillendirmede önemli bir rolü vardır. Bu nedenle eşitsizlik sorunu, sadece sosyal ve ekonomik açıdan değil eğitim açısından da önemli konulardan biri haline gelmiștir. Eğitimdeki eșitsizliğin giderilmesi için politika yapıcılar ve uygulayıcılar eğitim ve diğer sosyal olanakların eşit dağılımını sağlamalıdır. Toplumların sahip oldukları sosyal, ekonomik ve kültürel sermaye bileșimi eğitimle etkileșim halindedir. Ayrıca, bilindiği gibi eğitim özellikle beșerî sermayenin geliștirilmesi konusundaki kilit unsurlardan biridir. Beșerî sermaye birikimi engellendiğinde meydana gelecek olan kayıplar telafi edilemez, bu yüzden nitelikli işgücüne ulaşma açısından eğitime önem vermemiz gerekmektedir. Ancak gerek eğitimin niteliği gerekse eğitime ulașım açısından tüm ülkelerde eșit koşullar sağlanamamaktadır. Bu nedenle, eğitimdeki eșitsizliğin yoğun olduğu ülkelerde insanların sahip oldukları zekâ, yetenek, kabiliyet farklılaşmakta ve beșerî sermayenin kalkınma ve büyüme sürecindeki etkileri sınırlandırılmaktadır.

Bu çalıșmada amacımız İnsani Gelişme Endeksinde alt bir endeks olarak hesaplanan ve eğitimin ülkede ortalama dağı̆lımı hakkında bilgi veren Eğitim Endeksi ile eğitimin dağılımına duyarlı olan Eşitsizlikle Uyumlandırılmış Eğitim Endeksinin ülkeler arası karşılaştııılmasıdır. Çalışmamızda ayrıca eğitim dağılımından kaynaklı kayıpların hangi ülke grupları için yüksek olduğu tespit edilecek ve bu ülkelerde daha eşit bir eğitimin sağlanması için çözüm önerileri getirilecektir.
\end{abstract}

Anahtar Kelimeler: Eğitim Eşitsizliği; İnsani Gelişme Endeksi; Eşitsizlikle Uyumlandırılmış Eğitim Endeksi

\section{Evaluation of Inequality in Education}

\begin{abstract}
Conditions such as wealth, gender, ethnicity, and location, of which people have little control, have an important role in shaping education and life opportunities. Therefore, the problem of inequality has become one of the important issues not only in terms of social and economic conditions but also in terms of education. Policymakers and practitioners should ensure the equal distribution of education and other social means in order to overcome inequality in education The social, economic and cultural capital composition of the societies interacts with education. Moreover, as is known, education is one of the key elements in the development of human capital. The losses that will occur when the accumulation of human capital is prevented cannot be compensated, so we need to give importance to education in terms of achieving qualified labor. However, equal conditions cannot be achieved in all countries in terms of both the quality of education and access to education. Therefore, in countries where there is a high level of inequality in education, the intelligence, ability, and ability of people are differentiated and the effects of human capital on development and growth process are limited.

In this study, it is aimed to compare the Education Index, which shows the average distribution of education in the country, and the Inequality-Adjusted Education Index, which is sensitive to the distribution of education, among the country groups. In addition, the losses due to the distribution of education will be evaluated for the country groups to provide policy proposals for more equal education.
\end{abstract}

Keywords: Education Inequality; Human Development Index; Inequality-Adjusted Education Index

\section{Giriș}

Eğitim, bilgi ve becerileri öğrenme ve öğretme sürecidir.

*Yazışma Adresi / Address for Correspondence:

Görkemli Kazar, Email: gorkemlikazar@munzur.edu.tr

Geliş Tarihi / Received Date: 08.04.2019

Kabul Tarihi / Accepted Date: 19.04.2019

Doi: $10.26701 /$ uad. 550541
Bu süreç, yeryüzünde insanın yaratılmasıyla başlamış, yavaş yavaş gelişip bugün toplumların ilerleyişinde temel yapı taşlarından biri haline gelmiştir (Gibson, 2006). Eğitim, temel insan haklarından biridir; sosyal ve ekonomik kalkınmanın temel bir bileşenidir ve özellikle gelişmekte olan ülkelerde büyük bir sosyal ve ekonomik dönüşüme yol açabilir (Psacharopoulos ve Woodhall, 1985). Eğitim, inançların, bilginin, bilgeliğin ve düşüncenin oluşumuna ve gelişmesine yardımcı olan bir araçtır. Eğitimin, bugü- 
nün dünyasında az gelişmişliğin ortadan kaldırılması için tek çözüm olduğu söylenebilir. Gerekli uzmanlık eksikliği, düşük eğitim ve bilgi düzeyleri ile bilimsel ve teknolojik gelişmelerin eksikliği günümüz dünyasında gelişmekte olan ülkeler için en önemli konular arasındadır (Zolfaghari ve Shatar Sabran, 2009). Eğitim, bir toplumun beşeri sermayesinin oluşumunda önemli bir rol oynar ve bu nedenle, kişilerin verimliliğini artırarak ve onları yetenekli bir insan gücü haline getirerek ülkenin sosyal ve ekonomik gelişimi için güçlü bir temel sağlar (Memon, 2007; Mankiw, Romer, ve Weil, 1992). Ayrıca, eğitim yeni teknolojiler, ürünler ve süreçlerle ilgili bilgiler sağlayarak ekonominin yenilikçi kapasitesini de artırır (Lucas (1988); Romer 1990; Aghion ve Howitt (1998)). Yeni bilgileri anlamak ve işlemek ise büyümeyi teşvik etmek için gereken bilginin yayılmasını ve iletilmesini kolaylaştırır (Nelson ve Phelps 1966; Benhabib ve Spiegel (2005)).

Her ne kadar yaklaşık yetmiş yıl önce, İnsan Hakları Evrensel Beyannamesi'nin 26. Maddesinde eğitiminin özgür ve değiştirilemez bir insan hakkı olduğunu ve ilköğretimin zorunlu olduğu ifade edilse de (Birleşmiş Milletler, 10 Aralık 1948) eğitimin bireysel, topluluk ve ulusal kalkınma için kilit bir katalizör olarak gücü son yüzyılda anlaşılmıştır (Sen 2000; Bowles \& Gintis 1976). Eğitim eşitliği ve eğitime erişim sorunu, eğitim alanında yeni kavramlar olmamasına rağmen son yıllarda ana amaç olarak belirlenmiştir. 1990 Jomtien Konferansı, 1995 Pekin Konferansı ve 2000 Dakar Çerçevesi gibi uluslararası toplantılar ve çalıştaylarda, tüm çocuklar için ilköğretime eşit erişim hakkını vurgulayan yeni uluslararası girişimler yaratılmıştır. Binyıl Kalkınma Hedefleri'nde ve Herkes İçin Eğitim (EFA)'da ortaya çıkan inisiyatifler, uluslararası standartlar, eğitime erişim ve erişimdeki eşitsizliğin devam etmesine küresel bir odaklanma getirmiştir. Binyıl Kalkınma Hedeflerinin iki ve üçüncüsü, okul içindeki evrensel erişimi ve toplumsal cinsiyet eşitliğini vurgulamıştır. Bu hedefler tüm çocukların iyi kalitede ilköğretime erişimlerini sağlamaya ve eğitim kayıtlarında cinsiyet eşitsizliklerini ortadan kaldırmaya odaklanmıștır (Birleşmiş Milletler, 2007). Bu gelişmeler ışığında, eğitim kalitesi, fırsatlar ve çıktılarda eşitlik elde etmek uzun zamandır ulusal hükümetlerin ve bağışçı kurumların hedefleri olmuştur. Buna yönelik olarak, Ekonomik İşbirliği ve Kalkınma Teşkilatı (OECD) ülkeleri tüm eğitim sektörlerinde yerel ve ulusal eğitim çabalarına büyük miktarda kamu ve özel fon ayırmıştır. Ancak, eğitime yönelik çabalar çoğu zaman başarısız olmuş ve az gelişmişlik paradoksları da dahil olmak üzere öngörülemeyen sonuçlara yol açmıştır.

Çalışmamızda eğitimdeki eşitsizlikler ve bu eşitsizlerden dolayı ortaya çıkan kayıpların ülke grupları açısından değerlendirilmesi amaçlanmıştır. $\mathrm{Bu}$ amaç doğrultusunda Birleşmiş Milletler Kalkınma Programı (UNDP) tarafından hesaplanan eğitim endeksi ile eşitsizlikle uyumlandırılmış eğitim endeksi ve eğitimdeki eşitsizlikten kaynaklanan kayıplar değerlendirilmiştir. Çalışmamızın ikinci bölümünde eğitim eşitsizliğini inceleyen literatür veri- lecektir. Üçüncü bölümde Birleşmiş Milletler Kalkınma Programının oluşturduğu eğitim endeksleri tanıtılacaktır. Dördüncü bölümde ülke grupları açısından eğitim durumu, eğitimdeki eşitsizlikler ve bunun ortaya koyduğu kayıplar açıklanacaktır. Sonuç bölümünde genel bulgular tartışılıp, öneriler sunulacaktır.

\section{LITERATÜR}

Eşitliği nicelik, sıralama, statü, değer veya derece bakımından eşit olma durumu olarak tanımladığımızda eğitimdeki eşitlik tüm eğitim seviyelerinde adalet ve dağılımının tarafsızlığı olarak değerlendirilebilir. Literatürde eğitimdeki eşitsizlikle ilgili öncü çalışmalar Coleman (1966, 1968); Bronfenbrenner (1973); Grisay (1984); Gewirtz, Ball ve Bowe (1995); ve Farrell (1999) tarafından yapilmıştır. Coleman (1968), okula giren toplulukların farkları, okulun ırk bileşimi, okulun çeşitli maddi olmayan özellikleri, ortak geçmişe ve yeteneklere sahip bireyler için okulun sonuçları ve okulun ortak geçmişe ve yeteneklere sahip olmayan bireyler için sonuçları olarak, beş eşitsizlik türü tanımlanmıştır. Bronfenbrenner (1973), eşitliğin eğitim dağılımının adaletini veya sosyal adaletini ifade ettiğini belirtmiştir. Grisay (1984), eğitimde beş eşitliği ilkesi tanımlamıştır: doğal eşitlik ilkesi, erişim ilkesi eşitliği, tedavi ilkesi eşitliği, başarı ilkesi eşitliği ve post-modern ilke. Gewirtz, Ball ve Bowe (1995) eşitlik ve adalet arasında bir ayrım yapmıştır. Eşitliğin gerçeklere, adaletin ise değerlere dayandığını ifade etmişlerdir. Farrell (1999) Bronfenbrenner'ın eşitsizlik tanımlarını desteklerken bu tanımların bireysel, alt grup veya grup perspektifine bağlı olarak farklılık gösterebileceğini ortaya koymuştur.

Eğitim eşitsizliğini ölçmeye yönelik öncü araştırmalarda Gini katsayılarını kullanmıştır. Maas ve Criel (1982), 16 Doğu Afrika ülkesi için Gini katsayılarını tahmin etmiştir. Rosthal (1978), ABD için tahmin edilen eğitim dağılımına ilişkin aralarında Gini katsayısı da bulunan dört göstergeyi özetlemiştir. Sheret (1988) Papua Yeni Gine için Gini katsayısını tahmin etmiştir. Bununla birlikte, yapılan çalışmalar çok sayıda ülke içermediği için eğitimdeki eşitsizliklerin karşılaştırılabilmesine imkân vermemiştir. Daha fazla ülkeyi kapsayan Eğitim Gini endeksi çalışmaları López, Thomas ve Wang (1998) ve Thomas, Wang ve Fan (2001) tarafından yapılmıştır. Bu çalışmalara göre eğitim Gini endeksi değerleri tam eşitliği temsil eden 0 ile tam eşitsizliği temsil eden 1 arasında değerler almıştır.

Bunun yanısıra, eğitimdeki eşitsizliğin ölçümü için Genelleştirilmiş Entropi (GE) yöntemi kullanılmıştır. Bu yöntemde, ortalama eğitim yılından büyük ölçüde farklılaşan ülkelerin ağırlıkları ortalamaya yakın olanlardan daha yüksek değer almaktadır. Buna göre, sıfır ile eşit bir dağılımı ve sıfırdan büyük değerler ise eğitimdeki eşitsizlik seviyesinin arttığını göstermektedir. Araujo, Ferreira ve Schady (2004) çalışmasında 124 ülkede hane halkı anketleri kullanılarak Gini ve GE değerleri hesaplanmıştır. Ayrıca, eğitimde eşitsizliğe yol açan çeşitli faktörler 
araștırmacılar tarafından incelenmiștir. Bunlar arasında Bourdieu 1977, Reagan 2005 ve Reay 2004 kültürün eğitim eşitsizliğine etkisini, Stromquist 2005 ve UNICEF 2007 cinsiyet-eğitim eşitsizliği ilişkisini, Carnoy 1999 ve Rambla 2006 küreselleşmenin eğitim eşitsizliğindeki rolünü incelemişlerdir. Bunların yanı sıra, politik ekonomi (Collins 2004; Holsinger 2005), politika (Dale 1989; Marginson ve Mollis) 2002), yoksulluk (Narayan 2000; Reimers 2000) ve özelleştirme (Belfield ve Levin 2002; Geo-JaJa 2004; Torche 2005) gibi faktörlerin de eğitim eşitsizliği üzerindeki etkileri araştırılmıştır. Sonuç olarak, hiçbir faktörün nihai olarak belirli bir ülkedeki eğitim ile ilgili yerel, bölgesel veya ulusal eşitsizlikleri açıklayamayacağı ve çoğu durumda eğitim eşitsizlikleri ile ilişkili karmaşıklıkları göstermek için çok değişkenli bir açıklama yapılması gerektiği sonucuna varılmıștır.

\section{EĞiTIM ENDEKSI VE EŞiTSIZLIKLLE UYUMLANDIRILMIŞ EĞiTIM ENDEKSI}

Ülkelerin gelişmişlik düzeylerine göre sınıflandırılmasında ve insani gelişmişlik düzeyinin ölçülmesi konusunda yapılan en önemli çalışmalar Birleşmiş Milletler tarafından yapılmıştır. Elde edilen bu çalışmaların sonucunda, tespit edilen bulgular da UNDP tarafından yayınlanan İnsani Gelişmişlik Raporları ile açıklanmıştır.

İlk kez 1990 yılında yayınlanan İnsani Gelişmişlik Raporunda (IGR), insan odaklı gelişmenin üzerinde durulmuştur. Birleşmiş Milletler Kalkınma Programı, gelişmenin sadece büyümeyle değil aynı zamanda ne tür büyümeyle değerlendirilmesi konusunda İnsani Gelişme Endeksi'ni (İGE) geliştirmiştir.

2011 yılından itibaren Eşitsizlikle Uyumlandırılmış Endeks değerleri oluşturulmaya başlanmış ve endeksler eşitsizlikler dikkate alınarak yeniden hesaplanmıştır. Eşitsizlikle Uyumlandırılmış Eğitim endeksinde İGE eğitim endeksi hane halkı anketleri sonucu okula gidilen yıl sayısı dağılımındaki eşitsizlikler dikkate alınarak uyumlandırılmıştır. (UNDP, 2011).

Bu uyumlandirma Foster, Lopez-Calva ve Szekely (2005) tarafından Atkinson (1970) eşitsizlik ölçütü temel alınarak yapılmıştır. Bireyler arasında eşitsizlik durumunda eşitsizlikle uyumlandırılmış insani gelişme endeksi değeri insani gelişme endeksi değerinin altına düșerken, eşitsizlik olmadığı durumda bu endeksler aynı değeri alırlar.

Atkinson (1970) eşitsizlik ölçütünü $A=1-g / \mu$ olarak tanımlamıştır. Geometrik ortalama $g$ ile aritmetik ortalama ise $\mu$ ile gösterilmektedir ve eşitsizlik aşağıdaki gibi tanımlanır:

$A_{x}=1-\frac{\sqrt[n]{X_{1} \cdot X_{2} \ldots X_{n}}}{\bar{X}}$

burada $\{X 1 \ldots, X n\}$ ilgilenilen dağılımın boyutlarını, $\mathrm{A}_{\mathrm{x}}$ ise Atkinson eşitsizlik ölçüsünü göstermektedir. Her değişken için (yaşam beklentisi, ortalama okula gidilen yl sayısı, kullanılabilir gelir, kişi başına tüketim) $A_{x}$ değeri hesaplanmaktadır (UNDP, 2018).

Boyut endekslerinin eşitsizlikle uyumlandırılabilmesi aşağıdaki gibi yapılmaktadır:

$$
\bar{X} .\left(1-A_{x}\right)=\sqrt[n]{X_{1} \cdot X_{2} \ldots X_{n}}
$$

Eşitsizlikle uyumlandırılmış endeks değeri ise aşağıdaki gibi hesaplanmaktadır:

$$
I_{x}^{*}=\left(1-A_{x}\right) \cdot I_{x}
$$

Bu durumda Eşitsizlikle Uyumlandırılmış eğitim endeksini aşağıdaki gibi yazabiliriz:

$I_{E}^{*}=\left(1-A_{E}\right) \cdot I_{E}$

Burada I* ${ }_{E}^{*}$ eşitsizlikle uyumlandırılmış eğitim endeksini, $A_{E}$ okula gidilen yıl sayısı dağılımındaki eşitsizlikleri, $I_{E}$ eğitim endeksini göstermektedir. Buna göre eğitimdeki eşitsizlik aşağıdaki gibi ifade edilebilir:

Eğitimdeki eşitsizlik $=1-\frac{\mathrm{I}_{E}^{*}}{I_{E}}=A_{E}$

\section{4. ÜLKELER ARASI EĞiTIM EŞiTSIZLIKLLERI}

UNDP insani gelişme endeks değerlerini dikkate alarak ülkeleri gelişmişlik düzeylerine göre dört sınıfa ayırmaktadır: Çok Yüksek İnsani Gelişme (endeks değeri 0.800 ve yukarısı), Yüksek İnsani Gelişme (endeks değeri 0.7000.799 arası), Orta Düzey İnsani Gelişme (endeks değeri 0.550-0.699 arası) ve Düşük Düzey İnsani Gelişme (endeks değeri 0.550'den düşük). Gelişme düzeylerine benzer şekilde bu ülkelerde eğitim düzeyleri de farklılaşmaktadır. $\mathrm{Bu}$ konuyu değerlendirmek amacıyla Şekil 1'de gelişme

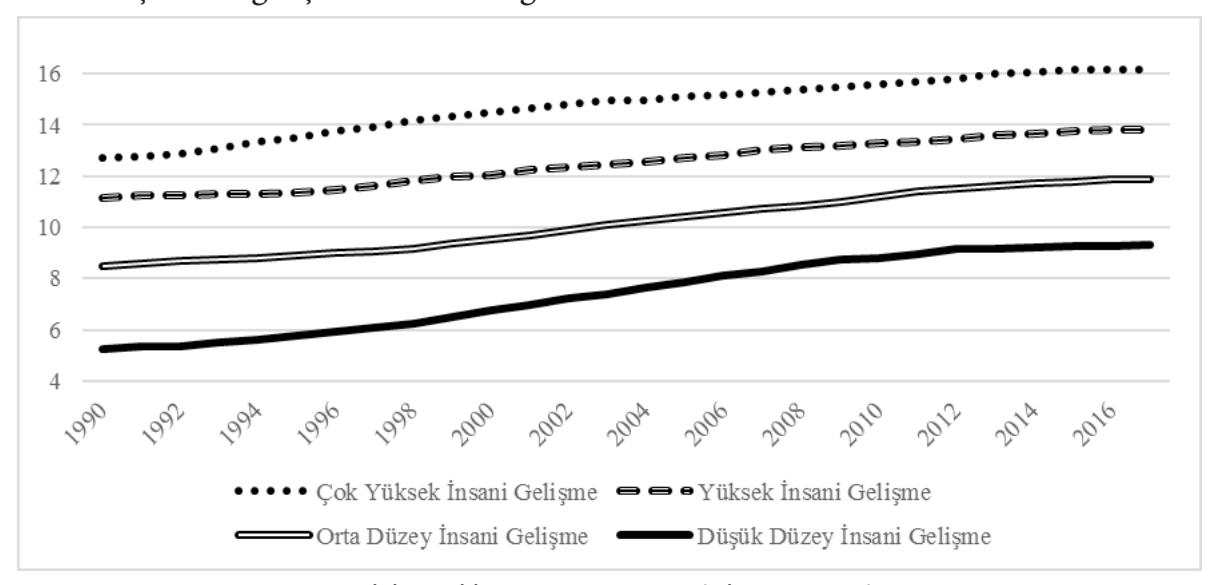

Şekil 1. Beklenen Eğitim Süresi (yıl, 1990-2017)

Kaynak: UNDP (2019) 


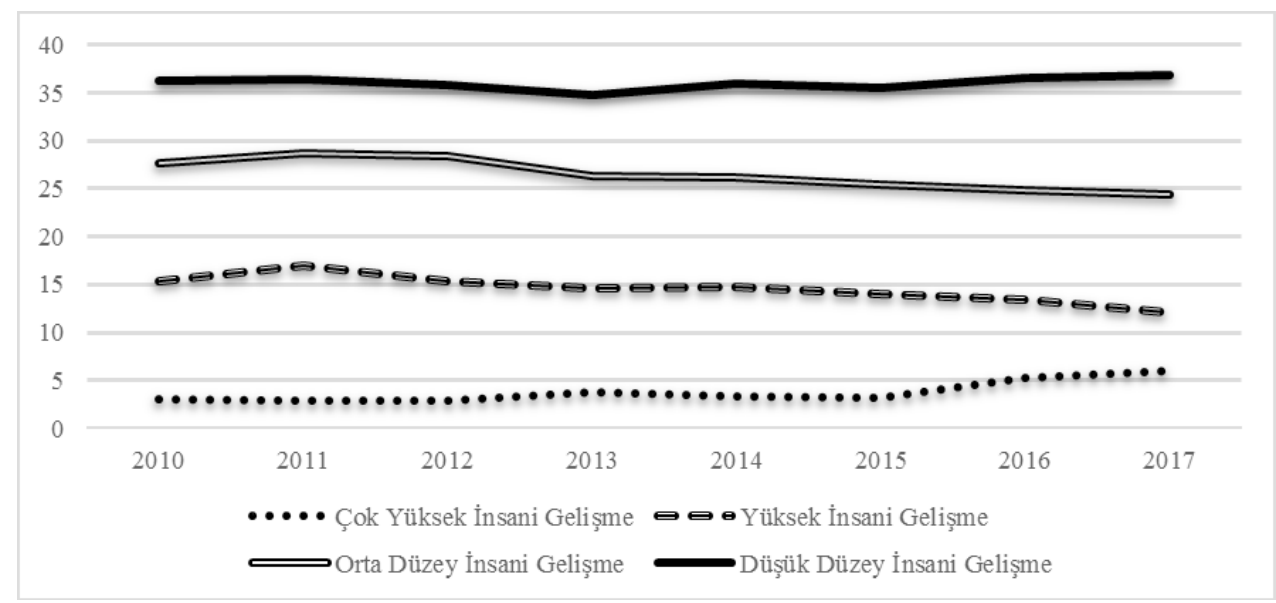

Şekil 2. Eğitimdeki Eşitsizlik Yüzdeleri (2010-2017) Kaynak: UNDP (2019)

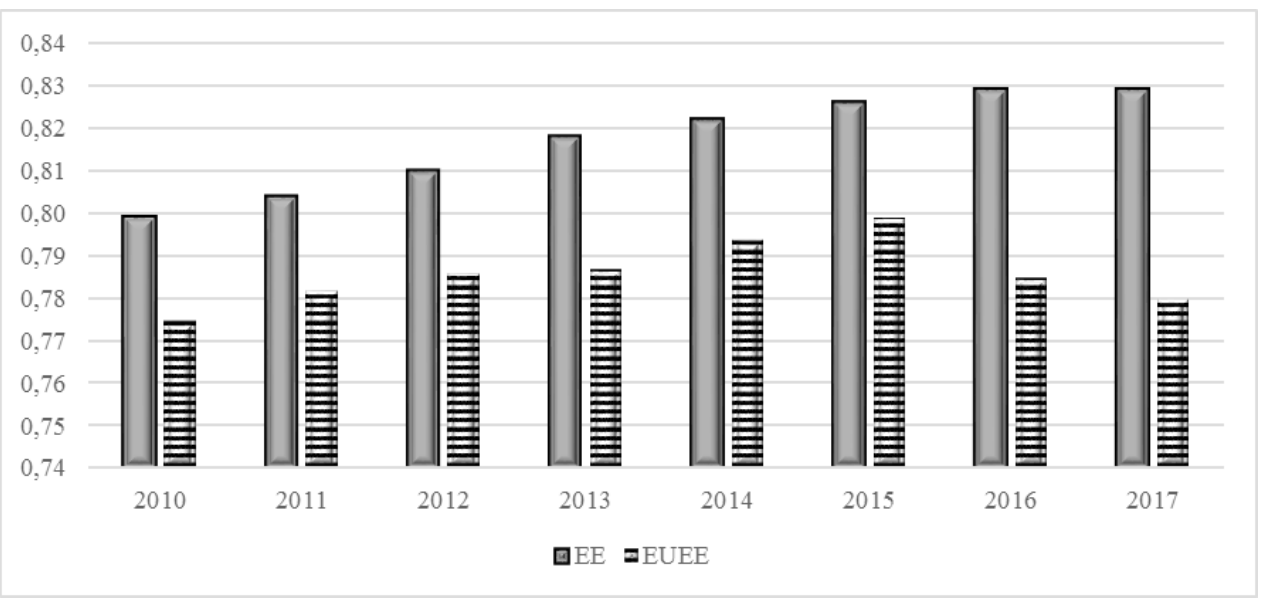

Şekil 3. Çok Yüksek İnsani Gelişme Gösteren Ülkelerin Eğitim Endeksleri (2010-2017) Kaynak: UNDP (2019); EE: Eğitim Endeksi, EUEE: Eşitsizlikle Uyumlandırılımış Eğitim Endeksi

düzeylerine göre ülkelerde beklenen eğitim süreleri verilmiştir.

Beklenen eğitim süresi açısından ülkeleri değerlendirdiğimizde 1990-2017 aralığında en büyük artış Düşük Düzey İnsani Gelişme gösteren ülkeler tarafından gerçekleştirilmektedir. Bunu sırasıyla Çok Yüksek İnsani Gelişme gösteren ülkeler ve Orta Düzey İnsani Gelişme gösteren ülkeler takip etmektedir. 1990 yılında Çok Yüksek İnsani Gelişme gösteren ülkeler ve Yüksek İnsani Gelişme gösteren ülkelerin eğitim beklentileri sırasıyla 12.70 yıl ve 11.17 yıl olarak gerçekleşmiştir. 2017 yılına gelindiğinde Düşük Düzey İnsani Gelişme gösteren ülkelerin henüz bu ülkelerin 1990 yılındaki eğitim seviyelerine bile erişemediği gözlemlenmektedir.

1990-2017 aralığındaki beklenen eğitim seviyeleri ülkeler arasında büyük uçurumlar yaratan bir diğer önemli etken ülkelerde eğitimin eşit şekilde dağılmamış olmasıdır. Eğitimde ülke içi eşitsizliklerin boyutları ve sonuçlarının anlaşılması açısından aşağıdaki grafikler oluşturulmuştur.

Eğitimdeki eşitsizlik özellikle düşük düzey insani gelişme gösteren ülkelerin sorunu olmakla beraber 2015 yılından sonra da çok yüksek insani gelişme gösteren ülkelerde de eğitimdeki eşitsizliğin artmaya başladığı anlaşılmaktadır. Yüksek insani gelişme gösteren ülkeler 2011 yılı itibariyle, orta düzey insani gelişme gösteren ülkeler ise 2012 yılı iti- bariyle eğitimdeki eşitsizliği azaltma çabalarında başarılı olmuşlardır.

Çok Yüksek İnsani Gelişme gösteren ülkeler için hesaplanan eğitim endeksi ve eşitsizlikle uyumlandırılmış eğitim endeksi değerlerinin de 2016-2017 yılları dışında artış eğiliminde olduğu görülmektedir. Eğitimdeki eşitsizlik ise bu ülkeler için dalgalı bir seyir izlemesine rağmen özellikle 2015 yılından sonra belirgin artışlar yaşanmış, bunun yol açtığı eşitsiz eğitimin ise uyumlandırılmış endeksin değerini olumsuz yönde etkilediği anlaşılmıștır.

Eğitim endeksi Yüksek İnsani Gelişme gösteren ülkeler için düzenli olarak artarken 2010 yılında Çok Yüksek İnsani Gelişme Gösteren ülkelerin yaklaşık beş katı eğitim eşitsizliğine tabi olan bu ülkeler özellikle 2014 yılı sonrası eşitsizliği azaltma konusunda başarı olmuşlardır. 2017 yılında karşı karşıya oldukları eğitim eşitsizliği düzeyi Çok Yüksek İnsani Gelişme gösteren ülkelerin iki katına gerilemiştir.

Orta düzey insani gelişme gösteren ülkeler 2010-2017 aralığında eğitim endekslerini geliştirmişlerdir. Benzer bir trend eşitsizlikle uyumlandırılmış eğitim endeksinde de gözlemlenmektedir. Bu olumlu gelişmenin büyük ölçüde eğitimdeki eşitsizliği özellikle 2011 yılından sonra aşamalı olarak azaltmalarına dayandığı görülmektedir. 2010 yılında \%27 düzeyinde olan eğitim eşitsizliğini 7 yll 


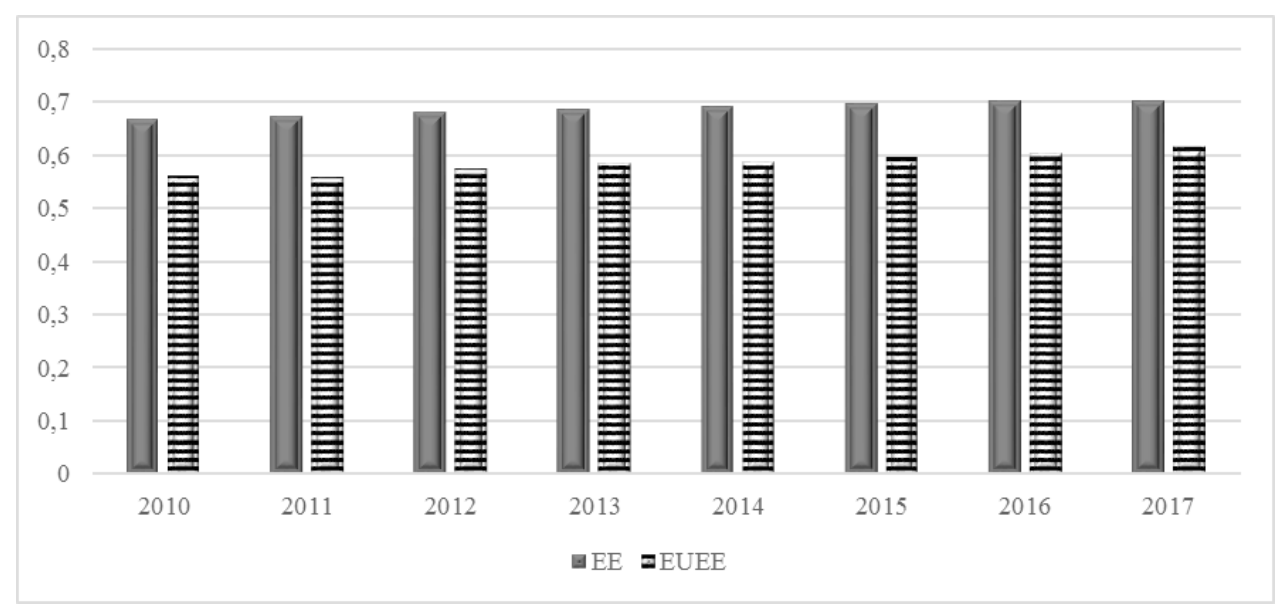

Şekil 4. Yüksek İnsani Gelişme Gösteren Ülkelerin Eğitim Endeksleri (2010-2017) Kaynak: UNDP (2019); EE: Eğitim Endeksi, EUEE: Eşitsizlikle Uyumlandırılmış Eğitim Endeksi

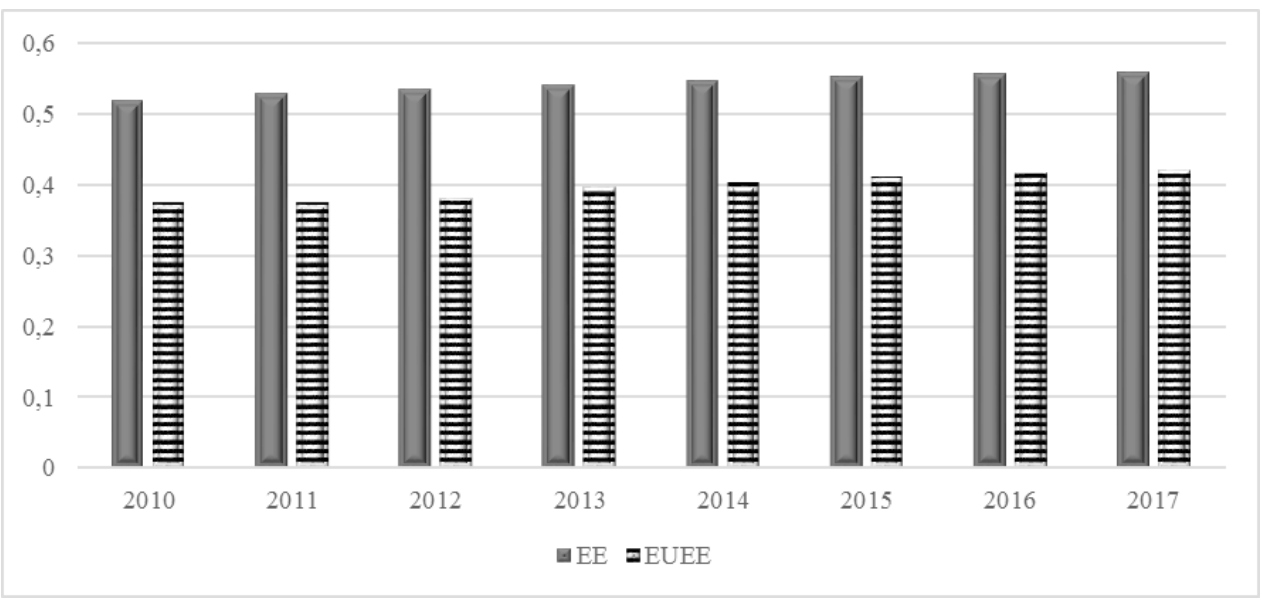

Şekil 5. Orta Düzey İnsani Gelişme Gösteren Ülkelerin Eğitim Endeksleri (2010-2017) Kaynak: UNDP (2019); EE: Eğitim Endeksi, EUEE: Eşitsizlikle Uyumlandırılmış Eğitim Endeksi

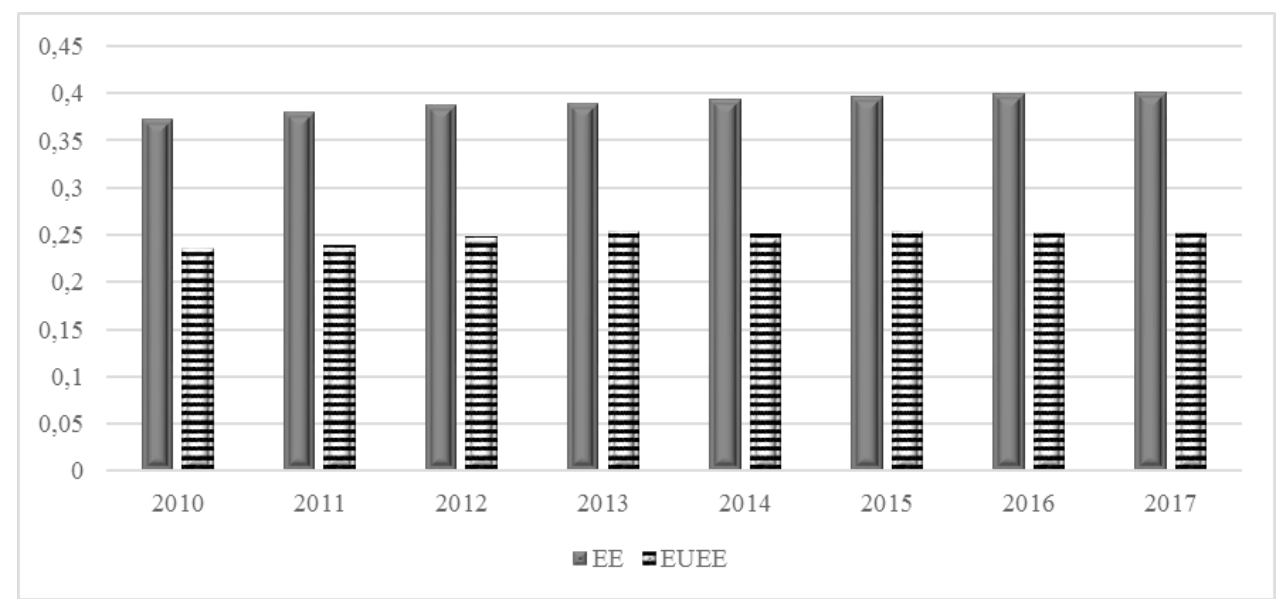

Şekil 6. Düşük Düzey İnsani Gelişme Gösteren Ülkelerin Eğitim Endeksleri (2010-2017) Kaynak: UNDP (2019); EE: Eğitim Endeksi, EUEE: Eşitsizlikle Uyumlandıııımış Eğitim Endeksi

içinde \%24 seviyelerine geriletmişlerdir. Ancak bu eșitsizlik düzeyinin çok yüksek insani gelişme gösteren ülkelerin 4 katı ve yüksek insani gelişme gösteren ülkelerin iki katı düzeyinde olduğu, bu yüzden bu ülkelerde eğitim eșitsizliğinin halen önemli bir sorun olarak ortada olduğu anlaşılmaktadır.

Düşük düzey insani gelişme gösteren ülkelerde 20102017 aralığında eğitim endeksi \%3’lük, eşitsizlikle uyum- landırılmış eğitim endeksi ise \%2'lik bir artış göstermiștir. Eğitim endeksindeki artış çok yüksek insani gelişme ve yüksek insani gelişme gösteren ülkelere yakın olmasına rağmen özellikle eşitsizlikle uyumlandırılmış eğitim endeksinde düşük düzey insani gelişme gösteren ülkelerin başarısız olduğu görülmektedir. Eğitimdeki eşitsizliğin incelenen dönem boyunca \%36 civarında olduğu ve 2015 yılı sonrasında eşitsizliğin boyutlarının giderek arttığı anlaşılmaktadır. 


\section{SONUÇ}

Yoksunluk ve eşitsizlik, sadece geliri değil aynı zamanda eğitim, sağlık ve diğer sosyal boyutların boyutlarını içeren çok boyutlu kavramlardır. Hem UNDP (2005) hem de Dünya Bankası (2006), fırsatların dağılımının kalkınma için anahtar olduğunu öne sürmüștür. Ancak, ülkeler içindeki ve ülkelerdeki her birey için mevcut firsatlarda büyük farklılıklar vardır. Dahası, mevcut kurumlar ve politikalar sonuçlarda mevcut eşitsizliklerin devam etmesine yol açan bir eşitsizlik tuzağı yaratılmıştır. Bu eşitsizlik tuzağı yoksulluğu ve eşitsizliği azaltma çabalarını engelleyerek ülkelerde sosyal istikrarsızlık kaynağı haline gelmiştir (Ravallion 1998, 2001; Ravallion ve Datt 2002; Chen ve Ravallion 2004; Ravallion ve Chen 2005). Eğitimsel alanda ise bu kısır bir eğitim eşitsizliği döngüsü olarak tanımlanmaktadır (Hershock, Mason ve Hawkins 2007). Buna yönelik olarak Binyıl Kalkınma Hedefleri, eğitim eşitliğinin küresel ölçekte gerçekleştirilmesi ve eğitimde standartların sağlaması amaçlarına odaklanılmasını sağlamıştır.

Çalışmamızda UNDP'nin gelişmişlik düzeyine göre s1nıflandırdığı ülkelerdeki eğitim eşitsizliği değerlendirilmiştir. Buna göre insani gelişme düzeyi arttıkça ülkelerde beklenen eğitim sürelerinin uzadığı ve eğitimdeki eşitsizliklerin azaldığı anlaşılmaktadır. Ülke grupları açısından ise eşit eğitime yönelik politikalarının özellikle Orta Düzey İnsani Gelişme ve Yüksek Düzey İnsani Gelişme gösteren ülkelerde başarılı olduğu görülmektedir. Düşük Düzey İnsani Gelişme gösteren ülkelerin kalkınmasını hızlandırmak için ortaya koyulan eğitim amaçlarının ise başarısız olduğu, böylece diğer ülke gruplarıyla eğitimde eşitliğin sağlanması açısından ıraksama yaşandığı görülmektedir.

Özellikle Düşük Düzey İnsani Gelişme gösteren ülkelerde eğitim eşitsizliğinin giderilememesi bu ülkelerde eğitim sisteminin bütüncül bir şekilde, toplumun, ekonominin, teknolojinin güncel durumuna ve gereklerine göre yeniden yapılandırılmasının gerekli olduğunu göstermektedir. Çünkü, ağırlıklı olarak bilgiye dayalı bir ekonominin etrafında dönen bir dünyada, geçmişe ait eğitim sistemleri bugünün ve gelecekteki sosyal ihtiyaçlar ve istihdam talepleri için yeterli değildir. Bu çerçevede, sosyal devlet anlayışının ve eğitim eşitliği ilkesinin bir ürünü olarak herkesin kaliteli ve eşit eğitimine erişiminin sağlanması öncelikli hedef olmalıdır. Ayrıca, bu ülkelerde ekonomik sektörlerin ihtiyaçlarına uygun işgücü yetiştirmek, sürekli eğitim, yetişkin eğitimi gibi alanlarda etkinliği arttırmak, işsiz gençlere hızlı meslek kazandırmak ya da onları kısa sürede işe yerleştirmek gibi katkılar sağlanmalıdır. Düşük Düzey İnsani Gelişme gösteren ülkelerin yapısal unsurları dikkate alınarak geliştirilecek eğitim politikaları ile iyi yetişmiş işgücü gereksiniminin karşılanmasının yanı sıra bu ülkelerin küreselleșen dünyada rekabet edebilmesi ve hızlı bir şekilde kalkınabilmeleri tetiklenebilir.

\section{KAYNAKÇA}

Aghion, P. \& Howitt, P. (1998). Endogenous Growth Theory.
Cambridge, Mass: MIT Press.

Araujo, C., Ferreira, F. \& Schady, N. (2004). Is the World becoming More Unequal? Changes in the World Distribution of Schooling. Working paper. Washington, DC: The World Bank.

Belfield, C.R. \& Levin, H.M. (2002). Education Privatization: Causes, Consequences and Planning Implications. Paris: International Institute for Educational Planning.

Benhabib, J. \& Spiegel, M.M. (2005). “Human Capital and Technology Diffusion." In Philippe Aghion and Steven N. Durlauf, eds., Handbook of Economic Growth. Amsterdam: North Holland.

Birleşmiş Milletler (2007). The Millennium Development Goals Report 2007. New York: United Nations.

Bourdieu, P. (1977). Cultural Reproduction and Social Reproduction, in Karabel, J. \& Halsey, A.H. (eds.), Power and Ideology in Education. New York: Oxford University Press, pp.485-511.

Bowles, S. \& Gintis, H. (1976). Education, Inequality, and the Meritocracy, in Schooling in the Capitalist America: Educational Reform and the Contradictions of Economic Life. New York: Basic Books, pp.102-124.

Bronfenbrenner, M. (1973). Equality and Equity. Annals of the American Academy of Political and Social Science, Vol.409, September, pp.5-25.

Carnoy, M. (1999). Globalization and Educational Reform: What Planners Need to Know. Paris: UNESCO.

Chen, S. \& Ravallion, M. (2004). How Have the World's Poorest Fared since the Early 1980s?. World Bank Research Observer, Vol.19, No.2, pp.141-170.

Coleman, J.S. (1966). Equality of Educational Opportunity. Washington, DC: Office of Education.

Coleman, J.S. (1968). The Concept of Equality of Educational Opportunity. Harvard Educational Review, Vol.38, No.1, pp.7-22.

Collins, R. (2004). Lenski's Power Theory of Economic Inequality: A Central Neglected Question in Stratification Research. Sociological Theory, Vol.22, No.2, pp.219-228.

Dale, R. (1989). The State and Education Policy. Philadelphia: Open University Press.

Farrell, J.P. (1999). Changing Concepts of Equality of Education: Forty Years of Comparative Education, in Arnove, R.F. \& Torres, C.A. (eds.), Comparative Education: The Dialectic of the Global and the Local. Lanham, MD: Rowman \& Littlefield, pp.149-177.

Geo-Jaja, M.A. (2004). Decentralisation and Privatisation of Education in Africa: Which Option For Nigeria?. International Review of Education, Vol.50, Nos.3/4, pp.309-325.

Gewirtz, S., Ball, S.J. \& Bowe, R. (1995). Markets, Choice and Equity. Buckingham, UK: Open University Press.

Gibson, P. (2006). Cruise operations management. Amsterdam; Boston: Elsevier Butterworth-Heinemann.

Grisay, A. (1984). Les mirages de l'education scolaire, Revue de la Direction Generale de l'Organisation des Etudes, XIX.

Holsinger, D.B. (2005). Inequality in the Public Provision of Education: Why It Matters. Comparative Education Review, Vol.49, No.3, pp.297-310. 
López, R.; Thomas, V. \& Wang, Y. (1998). Addressing the Education Puzzle: The Distribution of Education and Economic Reform. Policy Research Working Paper 2031. Washington, DC: The World Bank.

Lucas, R.E. (1988). On the Mechanics of Economic Development. Journal of Monetary Economics, 22: 3-42.

Maas, J.L. \& Criel, C. (1982). Distribution of Primary School Enrollments in Eastern Africa. World Bank Staff Working Papers, no.511. Washington, DC: The World Bank.

Mankiw, N.G., Romer, D. \& Weil, D. (1992). A Contribution to the Empirics of Economic Growth. Quarterly Journal of Economics, 107 (2): 407-37.

Marginson, S. \& Mollis, M. (2002). The Door Opens and the Tiger Leaps: Theories and Reflexivities of Comparative Education for a Global Millennium. Comparative Education Review, Vol.45, No.4, pp.581-615.

Memon, G. R. (2007). Education in Pakistan: The Key Issues, Problems and the New Challenges. Journal of Management and Social Sciences, 3(1), 47-55

Narayan, D. (2000). Voices of the Poor: Can Anyone Hear Us?. New York: Oxford University Press.

Nelson, R.R. \& Phelps, E. (1966). Investment in Humans, Technology Diffusion and Economic Growth. American Economic Review, 56 (2): 69-75.

Psacharopoulos, G., \& Woodhall, M. (1985). Education for development: an analysis of investment choices. New York: Published for the World Bank [by] Oxford University Press.

Rambla, X. (2006). Globalization, Educational Targeting, and Stable Inequalities: A Comparative Analysis of Argentina, Brazil, and Chile. International Review of Education, Vol.52, Nos.3-4, pp.353-370.

Ravallion, M. \& Chen, S. (2005). Hidden Impact: Household Saving in Response to a Poor-Area Development Project. Journal of Public Economics, Vol.89, Nos.11-12, pp.21832204.

Ravallion, M. \& Datt, G. (2002). Why has Economic Growth been more Pro-Poor in Some States of India than Others? Journal of Development Economics, Vol.68, No.2, pp.381400.

Ravallion, M. (1998). Does the Aggregation Hide the Harmful Effects of Inequality on Growth?. Economics Letters, Vol.61, No.1, pp.73-77.

Ravallion, M. (2001). Growth, Inequality and Poverty: Looking Beyond Averages. World Development, Vol.29, No.11, pp.1803-1815.

Reagan, T. (2005). Non-Western Educational Traditions: Indigenous Approaches to Educational Thought and Practice (3rd edition). Mahwah, NJ: Lawrence Erlbaum Associates.

Reay, D. (2004). Education and Cultural Capital: The Implications of Changing Trends in Education Policies. Culture Trends, Vol.13, No.2, pp.73-86.

Reimers, F. (2000). Unequal Schools, Unequal Chances: The Challenges to Equal Opportunity in the Americas. Cambridge, MA: Harvard University Press.

Romer, P. (1990). Endogenous Technological Change. Journal of Political Economy, 99 (5): S71-102.
Rosthal, R.A. (1978). Measures of Disparity. A Note. Research report published by Killalea Associates, Inc., ED149482, ERIC database.

Sen, A. (2000). Development as Freedom. New York: Random House.

Sheret, M. (1988). Equality Trends and Comparisons for the Education System of Papua New Guinea. Studies in Educational Evaluation, Vol.14, No.1, pp.91-112.

Stromquist, N.P. (2005). A Social Cartography of Gender in Education: Reflections on an Uncertain Emancipatory Project. Eggertson Lecture Paper presented at the Annual Comparative and International Educational Society Conference, Stanford University, CA, 23 March 2005.

Thomas, V.; Wang, Y. \& Fan, X. (2001). Measuring Education Inequality: Gini Coefficients of Education. Policy Research Working Paper 2525. Washington, DC: The World Bank.

Torche, F. (2005). Privatization Reform and Inequality of Educational Opportunity: The Case of Chile. Sociology of Education, Vol.78, No.4, pp.316-343.

UNDP (2018). Human Development Indices and Indicators. Washington DC: United Nations Development Programme.

UNDP (2019). Human Development Data (1990-2017). Erişim adresi: http://hdr.undp.org/en/data

UNESCO (2000). The Dakar Framework for Action Education for All: Meeting our Collective Commitments. Paris: UNESCO.

UNICEF (2007). The State of the World's Children 2007: The Double Dividend of Gender Equality. New York: UNICEF.

United Nations (2007). The Millennium Development Goals Report 2007. New York: United Nations.

Zolfaghari, A., \& Shatar Sabran, M. (2009). Community Learning Centers Program and Community Literacy Development in the Islamic Republic of Iran. Kuala Lumpur: Global Press. 